\title{
Examining University Students' Self-Compassion and Compassionate Love Levels in Terms of Perceived Parental Attitudes*
}

\author{
Halime Eker ${ }^{1}$, Mehmet Kaya ${ }^{2}$ \\ ${ }^{1}$ İstanbul Kültür University, İstanbul, Turkey \\ ${ }^{2}$ Sakarya University, Sakarya, Turkey \\ Correspondence: Halime Eker, Department of Educational Sciences, İstanbul Kültür University, 34158 Bakırköy, \\ İstanbul, Turkey.
}

Received: August 1, 2018

doi:10.11114/jets.v6i11.3407
Online Published: September 12, 2018

URL: https://doi.org/10.11114/jets.v6i11.3407

\begin{abstract}
The aim of this research is to investigate the relationship between parental attitudes perceived by the students, self-compassion and compassionate love levels, and differences occur in parental attitudes, self-compassion and compassionate love levels according to various variables. The research was conducted with 326 university students studying in different departments of Sakarya University Faculty of Education. Parental Attitude Scale (PAS), Self-Compassion Scale (SCS), the Compassionate Love Scale (CLS) and Information Collection Form were applied in the study. The research data were analyzed by correlation, T-test and One Way (ANOVA). The results of the research revealed that the self-compassion level of the students who perceived the parents' attitudes as democratic was high, whereas the self-compassion level of the students who perceived the parental attitudes as authoritarian and protective-demanding was low. It was also found out that the students who perceived their parents' attitudes as authoritarian and protective-demanding had high compassionate love levels. The present study demonstrated the authoritarian and protective-demanding parental attitudes perceived by university students differed according to sex, the democratic parental attitude differed in terms of the number of siblings, and the compassionate love differed in terms of gender. It was revealed that there was a negative relationship between self-compassion and compassionate love.
\end{abstract}

Keywords: parental attitudes, self- compassion, compassionate love

\section{Introduction}

The family is considered as the most important environment and institution in terms of the psychological development of the child (Hess and Holloways, 1984). There is an interaction between parents and children in the family. For this reason, in the first years of life when children's specific attitudes and behaviours are beginning to emerge, the family has an important shaping effect on children (Dönmezer, 1999). Such that, the parental attitudes promote formation and characterization of the child's personality (Yavuzer, 1996).

\subsection{Parental Attitudes}

It is very likely to see that parental attitudes towards the child varies across parents. In fact, there are as many child-rearing styles as the number of parents, and resulted from this fact, it is also possible to see each of the parents (mother-father) can also exhibit different types of child rearing styles towards their children (Şendil, 2003). Common parental attitudes can be summarized as; democratic, authoritarian, overprotective, over-tolerant, permissive, careless-indifferent, perfectionist, refutative and unstable-inconsistent attitude.

Parents with democratic attitude recognize their children as a separate individual and support them to develop an independent personality (Kulaksızoğlu, 1999). In the authoritarian parental attitude, it is expected that the children obey and follow the rules unconditionally set by the parents (Şendil, 2003). Parents who adopt an overprotective attitude meet the needs of the child with excessive control, care and attention to the child (Navaro, 1989). In a family environment where there is an over-tolerant parental attitude, there is no prescribed limit set by the parents to control children's behaviours and the family members tend to comply with the wishes of the children (Dinçer, 2008). Parents

*This study is derived from the postgraduate thesis. 
with permissive attitude do not monitor their children and allow their children to do whatever they want (Şendil, 2003). Parents with careless-indifferent attitude display little attention to children's interests and needs. Moreover, they do not allocate enough time to their children and have as little relationship with them as possible (Dönmezer, 1999). Parents with a perfectionist attitude are never satisfied with the achievement of their children. They generally do not build up realistic expectations that pay regard to the child's age, level of development and talents (Çağdaş, 2002). Parents with refuting attitude do not accept their children and behave in a limiting, indifferent, aggressive and careless manner to them (Örgün, 2000). In unstable and inconsistent attitude, parents do not exhibit a consistent and balanced attitude (Dönmezer, 1999).

\subsection{Self-Compassion}

The attitudes and behaviors displayed by parents influence the way children approach themselves. The concept of self-compassion appears to be an alternative to psychological well-being. Self-compassion involves being open to the emotions that lead to the suffering of the individual, to be loving and polite towards himself/herself, to be in an attitude of understanding and non-judgemental against errors and inadequacies, and to accept that the individual's own life is the part of the common life of all mankind (Neff, 2003a). Self-compassion requires that the acceptance of suffering, failure and inadequacies are part of being human, and that all the individuals, including oneself, deserves compassion (Goldstein and Kornfield, 1987).

Self-compassion involves three sub-dimensions:

1. To be kind and understanding toward oneself rather than being harshly self-critical and judgemental

2. To be able to see his/her experiences as a part of humanity rather than isolating and alienating himself/ herself from other people

3. To have a balanced mindfulness rather than an over-identification with painful emotions and thoughts (Neff, 2003a).

Neff (2003a) defines three sub-dimensions; self-kindness, awareness of common humanity and mindfulness. Self-kindness is to be kind and understanding toward oneself rather than being harshly self-critical and judgemental. When one realizes any disliking feature in himself/herself, he/she treats his/her mistakes kindly and uses a soft, supportive language while talking to himself/herself. The second component of self-compassion called "awareness of common humanity" implies that no one is perfect, everybody can fail and can make mistakes (Neff, 2009). The third dimension of mindfulness is a pre-conceptual consciousness that permits the individual to accept stressful and painful emotions without over-identifying with them (Gunaratana, 1993; Martin, 1997; Neff, 2003a; Nisker, 1998; Rosenberg, 1999). Mindfulness is a balanced state of awareness in which the individual follows his/her emotions and thoughts without exaggerating, negatively judging them and not refraining them or changing them (Neff, Hsieh and Dejitterat, 2005).

Self-compassion is negatively associated with self-recrimination, depression, anxiety, rumination and thoughts suppression while positively associated with social relation, emotional intelligence and self-determination (Neff, 2003a). Other studies also show that self-compassion is negatively associated with performance-approach/avoidance aims (Akın, 2008) and submissive behaviour (Akın, 2009) whereas it manifests positive relation with self-deception (Akın and Abac1, 2009) and learning-approach aims (Akın, 2008) are negatively related to.

\subsection{Compassionate Love}

Parental attitudes that shape the child's self-assessment also affect the sensitivity towards other individuals. At this point, compassionate love need to be defined. Compassionate love is defined as an attitude that includes feelings, thoughts, and attitudes that are focused on care, interest, sensitivity and other people's support, help, and understanding of other people, especially when other people suffer and need help. It has features such as compassionate love, self-sacrifice, helpfulness, care, interest, empathy, sympathy and sensitivity (Fehr and Sprecher, 2009).

Compassionate love has significant social, individual, and health outcomes and are not reducible to other types of affection or positive social characteristics (Fehr et al., 2008). To illustrate, compassionate love should not be deemed as romantic love because it is conceptually richer than an altruistic love that can only be performed as a habit (Underwood, 2008).

The concepts of empathy and sympathy are defined as different psychological processes that are related to compassionate love (Nickolas, 2009). Unlike empathy, compassionate love shows continuity because compassionate love is felt without a specific purpose whereas empathy occurs in a particular situation such as when someone suffering seen (Sprecher and Fehr, 2005). In sympathy, however, regardless of whether you understand it, you tend to give right to that person in any case. It is not necessary to understand the person who is sympathized, it is essential to be ardent advocator of this person (Dökmen, 1997). Sprecher and Fehr (2005) state that compassionate love is a behavioural tendency that encompasses constantly felt sensitivity and care to the others.

Compassionate love is a constant condition and it is a state of volunteerism towards strangers and social support for 
loved ones, which contributes to positive social behaviours. Compassionate love is considered a strong motivation to help and support other people, both foreigners and those close to them (Sprecher and Fehr, 2005). It was found that people feeling compassionate love have an increased positive self-esteem, good mood, more positive relationships, improved health, and increased spirituality (Fehr and Sprecher, 2008).

\section{Method}

\subsection{Sub Problems}

This study seeks answer to the following sub-problems.

1. Are there statistically significant relationships between parental attitudes, self-compassion and compassionate love levels of university students?

2. Do parental attitudes, levels of self-compassion and compassionate love differ according to gender?

3. Do parental attitudes perceived by university students, levels of self-compassion and compassionate love differ significantly by the number of siblings?

\subsection{Research Model}

In this study, the relationship between parental attitudes perceived by students, self-compassion levels, compassionate love levels, and differences emerge in parental attitudes and levels of self-compassion and compassionate love according to various variables were also examined. The research was conducted in accordance with the Comparative Relational Screening Model. This research model aims to determine the presence and / or degree of exchange between two or more variables (Karasar, 2010).

\subsection{Study Group}

The sample of this research consists of 326 university students, of whom 230 are girls and 96 are males, who are randomly selected and training in various parts of the Sakarya University Faculty of Education. Accessibility and affordability were taken into consideration in the selection of the students who participated in the study.

\subsection{Data Collection Tools}

Data were obtained through Self-Compassion Scale (SCS) about the level of self-efficacy of the participants and Parental Attitude Scale (PAS) about the perceived parental attitudes and the Compassionate Love Scale (CLS) about the level of compassionate love. Information Collection Form was used to determine the demographic characteristics of the participants.

\subsubsection{Information Collection Form}

In this form, participants are asked questions such as gender and sibling number to determine socio-demographic information of the participants.

\subsubsection{Parental Attitude Scale}

The parental attitude scale (PAS) developed by Kuzgun (1972), which was later updated by Eldeleklioğlu (1996), was used to measure parental attitudes in the study. Eldeleklioğlu (1996) also added 3 dimensions; protective, willing and refutative parental attitudes to 'democratic', 'authoritarian', " indifferent" sub-dimensions previously stated by Kuzgun (1972). A total of five subscales were identified and 119 items describing these subscales were written, including 35 democratic, 29 authoritarian, 12 protective-demanding, 12 refutative, and indifferent.

The internal consistency of the Parental Attitude Scale was calculated using the Cronbach Alfa formula, and the alpha values were found as. 89 for the democratic attitude subscale, .82 for the protective-demanding attitude subscale, and. 78 for the authoritarian attitude subscale. Test retest method was used to measure the level of stability of the scale. The coefficient of stability was found as .92 for the democratic attitude subscale, .75 for the protective-demanding attitude subscale, and. 79 for the authoritarian attitude subscale. As a result of the factor analysis, the factor loadings of the refutative and indifferent subscales were not found satisfactory enough, so the items in this subscale were subtracted from the scale. For the Democratic and Protective-demanding subscale, the factor load was 15 as the highest rate for each, while for the Authoritarian subscale, 10 items were selected and a total of 40 items of parental attitude scale were created. It was found that there was a correlation of -0.64 between the democratic subscale scores and the authoritarian subscales, and a correlation of. 36 between the democratic subscale scores and the authoritarian subscale scores.

The responses to the items were arranged to be rated on a 5-point Likert-type scale. The answers for each item were rated as; Not appropriate (1), Slightly appropriate (2), Partially appropriate (3), Pretty much appropriate (4), Absolutely appropriate (5). By reading each item from the subjects, they were requested to choose the most appropriate expression for their parents (Kuzgun ve Bacanlı, 2005). 


\subsubsection{Self-Compassion Scale}

Self-compassion is measured by means of the Self-Compassion Scale developed by Neff (2003b). In the CFA for the Self-Compassion Scale that is comprised of 26-item measurement instrument, the presence of 6 sub-dimensions constituting the self-compassion structure was verified: self-judgement against self-kindness, alienation against awareness of common humanity, and over- identification against mindfulness.

The Self-Compassion Scale was adapted to Turkish by Akın, Akın and Abacı (2007) has item-total correlations found between .48 and .71 and the differences in the $27 \%$ item scores of sub-group and super-group $t(\mathrm{sd}=320)$ was found to be between $16.11(\mathrm{p}<.001)$ and $29.57(\mathrm{p}<.001)$.

In order to examine the construct validity of the scale, the KMO sample suitability coefficient for AFA was .66 and the Barlett Sphericity test for $\chi^{2}$ value was found to be $15464.500(\mathrm{p}<.001)$. As a result of the analysis, a measuring instrument consisting of 26 items and 6 subscales, which explained $68 \%$ of the total variance, was obtained. Conformity indices obtained from DTA were examined. And Chi-square value $(\mathrm{x} 2=779.01, \mathrm{~N}=633, \mathrm{sd}=264, \mathrm{p}=0.00)$ was found to be significant. The Fit index values of the model were found as RMSEA $=.056, \mathrm{NFI}=.95, \mathrm{CFI}=.97, \mathrm{IFI}=.97, \mathrm{RFI}=.94, \mathrm{GFI}=.91$ and $\mathrm{SRMR}$ $=.059$. Internal consistency reliability coefficients of the Self-compassion Scale was found .77 for Self-compassion subscale, .72 for self-judgement .72 for consciousness of sharing, .80 for isolation, .74 for mindfulness, and .74 for over-identification. Test-retest reliability coefficients of the scale were found as .69 for self-kindness subscale, .59 for self-judgement, .66 for sharing awareness, .60 for isolation, .69 for mindfulness and .56 for over-identification.

\subsubsection{The Compassionate Love Scale}

The Compassionate Love Scale, which is 7-point Likert scale (1 is totally incorrect for me -7 is totally correct for me), consists of 21 items, and scores of all the items in the scale can be summed up to obtain a total compassionate love score. The range of probable scores in the measurement ranged from 21 to 147 . The high scores obtained from the scale indicate that the level of compassionate love of the individual is high. The internal consistency reliability coefficient of the scale was found as .95. The scale was adapted to the Turkish language by Akın and Eker (2012). The findings obtained from the linguistic equivalence study of the Turkish form show that the correlation coefficients between Turkish and the original forms ranged between .77 and .97 , and the linguistic equivalence score for the scale was found as .93. Item analysis revealed that the adapted item-test correlations ranged from .28 to .70 . The internal consistency reliability coefficient of the scale was .89 and the test-retest reliability coefficient was .82 .

Exploratory factor analysis (EFA) and confirmatory factor analysis (CFA) were performed to investigate the construct validity of Compassionate Love Scale. As a result of the exploratory factor analysis, a one-factor structure of 21 items with an eigenvalue over 1.00 and explaining $36.47 \%$ of the total variance was obtained. The factor loadings of the items vary between .41 and .78 . Since the factor load of the seventh and eighth items did not cover the .30 criteria, these items were kept on the scale, yet not included in scoring. Conformity index of the model were found as RMSEA $=.079$, NFI $=.94, \mathrm{CFI}=.96, \mathrm{RFI}=.93$ and $\mathrm{SRMR}=.063$.

\subsection{Data Analysis}

The Pearson Moments Multiplication Correlation was employed to examine relationships between parental attitudes, self-compassion and compassionate love levels of students and T- test was used to determine whether parental attitudes, self-compassion and compassionate love levels showed a significant difference in terms of gender. ANOVA was used to determine whether the students' parental attitudes, self-compassion and compassionate love levels displayed a significant difference in terms of the number of siblings. The data were analysed with the SPSS 11.5 package program.

\section{Findings}

\subsection{First sub-problem}

Are there statistically significant relationships between parental attitudes, self-compassion and compassionate love levels of university students?

Findings obtained from correlations executed to determine the relationships between parental attitudes, self-compassion and compassionate love levels perceived by university students are given in table 1.

According to Table 1, parental attitudes perceived by university students seem to be significantly related to self-compassion and compassionate love levels. The findings above indicate that self-compassion is positively associated with democratic parental attitude while it is negatively correlated with protective-demanding and authoritarian parental attitude. Moreover, when there was no significant relationship between compassionate love and democratic parental attitude, it was determined that there was a positive correlation between compassionate love and protective-demanding and authoritarian parental attitudes. Finally, it was found that self-compassion is negatively related to compassionate love. 
Table 1. Findings related to correlations between variables

\begin{tabular}{|c|c|c|c|c|c|}
\hline Factors & 1 & 2 & 3 & 4 & 5 \\
\hline 1. Democratic attitude & - & & & & \\
\hline 2. Protective-demanding & $-.282 * *$ & - & & & \\
\hline 3. Authoritarian & $-.531 * *$ & $.692 * *$ & 一 & & \\
\hline 4. Self-compassion & $.329 * *$ & $-.350 * *$ & $-.375^{* *}$ & - & \\
\hline 5. Compassionate love & -.092 & $.173 * *$ & $.237 * *$ & $-.126 *$ & 一 \\
\hline Mean & 57.19 & 36.92 & 19.74 & 84.56 & 61.80 \\
\hline Standard Deviation & 10.95 & 10.46 & 7.47 & 14.94 & 21.63 \\
\hline
\end{tabular}

Do parental attitudes, levels of self-compassion and compassionate love differ according to gender?

The "T" test technique was used to investigate whether parental attitudes, self-compassion and compassionate love levels perceived by university students differed in relation to the gender variable.

Table 2. T-test table for comparison of the differences between variables in terms of gender

\begin{tabular}{lccccccc}
\hline Variable & Gender & $\mathrm{N}$ & $\bar{X}$ & $\mathrm{Ss}$ & $t$ & $\mathrm{Sd}$ & $p$ \\
\hline \multirow{2}{*}{ Democratic attitude } & Male & 96 & 56.27 & 10.19 & -.979 & 324 & .328 \\
& Female & 230 & 57.57 & 11.25 & & & \\
Protective-demanding attitude & Male & 96 & 40.85 & 10.12 & 4.514 & 324 & .000 \\
& Female & 230 & 35.28 & 10.18 & & & \\
Authoritarian attitude & Male & 96 & 22.34 & 8.31 & 4.172 & 324 & .000 \\
& Female & 230 & 18.65 & 6.82 & & & \\
Self-compassion & Male & 96 & 83.36 & 14.74 & -.939 & 324 & .348 \\
& Female & 230 & 85.06 & 15.02 & & & \\
Compassionate love & Male & 96 & 67.63 & 24.46 & 3.184 & 324 & .002 \\
& Female & 230 & 59.37 & 19.89 & & & \\
& & &
\end{tabular}

Table 2 shows mean and standard deviations of the university students regarding parental attitudes, levels of self-compassion and compassionate love in terms of gender variable. Upon examination of the table, it can be seen that there is not a significant difference between male and female university students in terms of democratic parental attitude while there is a significant difference in terms of protective-demanding and authoritarian parental attitudes. In addition, there is no significant difference between male and female university students in terms of self-compassion. On the other hand, the table demonstrates that there is a significant difference between male and female university students in terms of compassionate love.

\subsection{Third Sub-problem}

Do parental attitudes perceived by university students, and levels of self-compassion and compassionate love differ significantly by the number of siblings?

ANOVA was used to determine the differences in parental attitudes perceived by university students, self-compassion and compassionate love levels when the number of siblings concerned. The findings of the ANOVA that shows whether there are significant differences in terms of democratic parental attitudes according to the number of siblings of students are shown in table 3.

Table 3. A table of variance analysis for comparing the scores of university students with different number of siblings in terms of variables

\begin{tabular}{|c|c|c|c|c|c|c|}
\hline Variable & Source of Variance & Sum of Squares & $\mathrm{Sd}$ & Average of Square & $\mathrm{F}$ & $\mathrm{p}$ \\
\hline \multirow{3}{*}{ Democratic attitude } & Between groups & 1726.940 & 4 & 431.735 & 3.723 & .006 \\
\hline & Within group & 37224.468 & 321 & 115.964 & & \\
\hline & Total & 38951.408 & 325 & & & \\
\hline \multirow{3}{*}{ Protective-demanding attitude } & Between groups & 503.191 & 4 & 125.798 & 1.152 & .332 \\
\hline & Within group & 35039.838 & 321 & 109.158 & & \\
\hline & Total & 35543.028 & 325 & & & \\
\hline \multirow{3}{*}{ Authoritarian attitude } & Between groups & 393.892 & 4 & 98.473 & & \\
\hline & Within group & 17736.058 & 321 & 55.253 & 1.782 & .132 \\
\hline & Total & 18129.950 & 325 & & & \\
\hline \multirow{3}{*}{ Self-compassion } & Between groups & 2001.964 & 4 & 500.491 & 2.279 & .061 \\
\hline & Within group & 70494.685 & 321 & 219.610 & & \\
\hline & Total & 72496.650 & 325 & & & \\
\hline \multirow{3}{*}{ Compassionate love } & Between groups & 1495.336 & 4 & 373.834 & .797 & .528 \\
\hline & Within group & 150598.704 & 321 & 469.155 & & \\
\hline & Total & 152094.040 & 325 & & & \\
\hline
\end{tabular}


In Table 3, as a result of the variance analysis conducted to determine the difference between the point average scores; parental attitudes, self-compassion and compassionate love levels of students with different number of siblings: single child, two siblings, three siblings, four siblings and five siblings and more, it was found that there is a statistically significant difference between students' mean scores of democratic parental attitudes. As a result of the Tukey Multiple Comparison Test conducted to determine the difference between the number of siblings, it was seen that difference resulted from the mean scores of the university students with two siblings and four siblings. There was no statistically significant difference between the mean scores of protective-demanding and authoritarian parental attitudes. There was also no statistically significant difference between the students' mean scores of self-compassion and compassionate love.

\section{Discussion, Results and Recommendations}

The findings of this study indicates that there is a significant relationship between self-compassion and democratic parental attitude. Children who grow up in a democratic environment are highly self-respecting, self-confident and self-regulating children. Due to these features, university students who perceive their parents as democratic are more likely to be sensitive to themselves. Yilmaz (2009) also found that there was a significant relationship between the degree of self- compassion level of university students and democratic parental attitudes.

This present research also demonstrates that there is a significant relationship between self-compassion and authoritarian parental attitudes. In over-authoritarian families, there are negative behavioural patterns such as negative judgements about the child's self, self-doubt, and hesitant behaviour in conveying thoughts to other people (Aslan, 1992). Self-compassion requires the individual to be non- judgemental and uncritical to himself. Instead, an individual with self-compassion treats himself/herself with politeness and understanding. In support of this view, the research conducted by Yilmaz (2009) also indicates that there is a negative relationship between self-compassion of the university students and authoritarian parental attitudes. According to this, it can be said that the students who are trained by authoritarian parental attitude exhibit low level of self-compassion. There was a negative relationship between self-compassion and protective-demanding parental attitude in the research. This finding is also supported by the findings of Yilmaz (2009) where self-compassion of the university students and protective parental attitudes were found to have a negative relationship.

It was determined that there was no significant relationship between compassionate love and democratic parental attitude whereas there was a significant relationship between compassionate love and authoritarian parental attitude. Considering that the individuals who grow up with authoritarian attitudes are insensitive to themselves and wish to gain the approval of their parents and other important persons, it may then be expected that these individuals are more sensitive to other people rather than being sensitive to themselves. Positive relationship between protective-demanding attitude and compassionate love was found.

Parents with protective-demanding attitude intervenes even when the child does not need their help. This approach makes it difficult for the child to be self-reliant, independent and self-sufficient (Navaro, 1989). It is possible to see that the children raised by parents with such attitude are more likely to show this excessive protection, help and sensitivity to others.

In the research, it was found that self-compassion is negatively related to compassionate love. Neff (2003a) defines self-compassion as being open to the painful experiences, being polite and understanding to himself/herself, approaching his/her failures and deficiencies with a non-judgemental attitude. Compassionate love focuses on the well-being of others (Underwood, 2008). Individuals who display high level of sensitivity to other people and focus on their well-being are thought to be insufficiently sensitive to themselves.

In this study, it was determined that there was no significant difference between female and male university students in terms of democratic parental attitude, but male university students perceived parental attitudes as authoritarian and protective compared to female students. In the study conducted by Yilmaz (2009), the same confirming result; that male university students perceive their parents' attitudes as protective and authoritarian compared to their female students had been found. It is understandable that male students perceive their parents' attitudes as authoritarian when we take into consideration the possibility of male students' bringing-up by their families with excessive pressure and strict discipline. On the other hand, it could be argued that compared to female, male is treated with more attention and care in our society. In the family settings where this child-rearing style is adopted, it is thought that the boys will perceive their parents' attitudes as protective because they will see more interest and protection.

There is no significant difference between male and female university students in terms of self-compassion. The results from this study further indicate that the compassionate love levels of men are higher than women. In the study conducted by Sprecher and Fehr (2005), it was seen that women scored more on the applied scale than men did.

In the research, it was found that the scores of democratic parental attitudes of university students with two sisters were higher than those of university students with four siblings, and the protective-demanding and authoritarian parental attitudes did not differ significantly according to the number of siblings. It was seen that the levels of self-compassion 
and compassionate love of the students did not differ significantly according to the number of siblings.

Parent's adoption of supporting and encouraging approach to their children to help them to cope with the problems and difficulties they encounter during the university period, in which youth problems are the most present, will contribute positively to ever-forming selfhood of their children and have these children gain the ability to cope with difficulties with more ease. Parents should have a democratic attitude in which the child is perceived as an independent individual, given unconditional love and value so as to promote their children to develop positive self-image, and thus with an increased self-compassion. In addition, psychological counselling studies for university students with low levels of self-compassion and compassionate love that affect their life and self negatively need to be put into practice.

It would be useful to investigate the emergence of new perspectives by using experimental method different from the method employed in this research. Also, doing such a study on a population outside the university would provide important contributions because it would be possible to have an insight to more comprehensive information about the formation, effects and positive-negative consequences of self-compassion and compassionate love.

\section{References}

Akın, A. (2008). Self-compassion and achievement goals: A structural equation modeling approach. Eurasian Journal of Educational Research, 31, 1-15.

Akın, A. (2009). Self-compassion and submissive behavior. Education and Science, 34(152), 138-147.

Akın, A., \& Abac1, R. (2009). Self-compassion and self-deception: A structural equation modeling. Paper Presented at the $1^{\text {st }}$ International Congress of Educational Research, Çanakkale.

Akın, A., \& Eker, H. (2012). Compassionate love scale: Validity and reliability study. Journal of Uludag University Faculty of Education, 25(1), 75-85.

Akın, Ü., Akın, A., \& Abacı, R. (2007). Self-compassion scale: The study of validity and reliability. Journal of Hacettepe University Faculty of Education, 33, 1-10.

Aslan, E. (1992). The concept of self and its effects on the life of the individual. Marmara University Atatürk Faculty of Education Journal of Educational Sciences, 4, 7-14.

Çağdaş, A. (2002). Parent-child communication. Ankara: Nobel Publications.

Dinçer, B. (2008). Investigation of high school second class teenagers with lower and upper socio-economic levels' perception of parental attitudes and friendship attitudes (Master's Thesis, University of Ankara, Ankara, Turkey). Retrieved from https://tez.yok.gov.tr.

Dökmen, Ü. (1997). Communication conflicts and empathy. İstanbul: Sistem Publishing.

Dönmezer, İ. (1999). Communication and interaction in family. İstanbul: Sistem Publishing.

Eldeleklioğlu, J. (1996). The relationship between decision strategies and parental attitudes. (Doctoral Dissertation, University of Gazi, Ankara, Turkey). Retrieved from https://tez.yok.gov.tr

Fehr, B., \& Sprecher, S. (2008). Compassionate love: Conceptual, measurement, and relationallissues. In B. Fehr, S. Sprecher, \& L.G. Underwood (Ed.), The Science of Compassionate Love: Theory, Research, and Applications (pp. 27-52), Malden, MA: Wiley-Blackwell. https://doi.org/10.1002/9781444303070

Fehr, B., \& Sprecher, S. (2009). Prototype analysis of the concept of compassionate love. Journal of Social and Personal Relationships, 16, 343-364. https://doi.org/10.1111/j.1475-6811.2009.01227.x

Fehr, B., Sprecher, S., \& Underwood, L. G. (2008). The science of compassionate love: Theory, research, and applications. Malden, MA: Blackwell. https://doi.org/10.1002/9781444303070

Goldstein, J., \& Kornfield, J. (1987). Seeking the heart of wisdom: The path of insight meditation. Boston: Shambhala.

Gunaratana, V. H. (1993). Sati. In mindfulness in plain English. Somerville, MA: Wisdom Publications.

Hess, R. D., \& Holloways, S. D. (1984). Family and school as educational institutions. In: R. D. Parke (Ed.), Review of Child Development Research, Chicago: University of Chicago Press, 7, 179-222.

Hu, L., \& Bentler, P. M. (1999). Cutoff criteria for fit indexes in covariance structural analysis: Conventional criteria versus new alternatives. Structural Equation Modeling, 6, 1-55. https://doi.org/10.1080/10705519909540118

Karasar, N. (2010). Scientific research method. Ankara: Nobel.

Kulaksizoğlu, A. (1999). Puberty psychology. İstanbul: Remzi Publishing house. 
Kuzgun, Y. (1972). The effect of parental attitudes on the level of individual's self-realization. ((Doctoral Dissertation, University of Hacettepe, Ankara, Turkey). Retrieved from https://tez.yok.gov.tr.

Kuzgun, Y., \& Bacanl1, F. (2005). Series of measuring instruments and programs used in counseling and psychological counselling. Ankara: Nobel Publishing Distribution.

Martin, J. R. (1997). Mindfulness: A proposed common factor. Journal of Psychotherapy Integration, 7, 291-312. https://doi.org/10.1023/B:JOPI.0000010885.18025.bc

Navaro, L. (1989). Effects of overprotection on child education. 6. Ya-pa Preschool Education and Dissemination Seminar. İstanbul: Ya-Pa Publishing.

Neff, K. D. (2003a). Self-compassion: An alternative conceptualization of a healthy attitude toward oneself. Self and Identity, 2(2), 85-102. https://doi.org/10.1080/15298860309032

Neff, K. D. (2003b). The development and validation of a scale to measure self-compassion. Self and Identity, 2(3), 223-250. https://doi.org/10.1080/15298860309027

Neff, K. D. (2009). Self-compassion. In M. R. Leary \& R. H. Hoyle (Ed.), Handbook of Individual Differences in Social Behavior. New York: Guilford Press.

Neff, K. D., Hseih, Y., \& Dejitthirat, K. (2005). Self-compassion, Achievement Goals, and Coping with Academic Failure, Self and Identity, 4, 263-287. https://doi.org/10.1080/13576500444000317

Nickolas, M. A. (2009). Fostering social support and compassionate love in the Greek Orthodox Church through small groups (Doctoral Dissertation, The Boston University, Boston).

Nisker, W. (1998). Mindfulness: The opposable thumb of consciousness (Chapter 3), In Buddha's nature: A practical guide to discovering your place in the cosmos (pp. 26-30). New York: Bantam Books.

Örgün, S. K. (2000). The Relationship between Parental Attitudes and Self Esteem and Assertiveness of Grade 8 Students (Master's Thesis, University of Marmara, İstanbul, Turkey). Retrieved from https://tez.yok.gov.tr.

Rosenberg, L. (1999). Breathing with the body (Chapter 1), In breath by breath: The liberating practice of insight Meditation (pp. 10-39). Boston: Shambala.

Sprecher, S., \& Fehr, B. (2005). Compassionate love for close others and humanity. Journal of Social and Personal Relationships, 22, 629-652. https://doi.org/10.1177/0265407505056439

Sümer, A. S. (2008). Assessment of Depression, Anxiety and Stress in University Students with Different Self-Compassion Levels (Master's Thesis, University of Selçuk, Konya, Turkey). Retrieved from https://tez.yok.gov.tr

Şendil, G. (2003). Child, youth and parent. İstanbul: Çantay Bookstore.

Underwood, L. G. (2008). Compassionate love: A framework for research, In B. Fehr, S. Sprecher, \& L. G. Underwood (Ed.), The Science of Compassionate Love: Theory, Research, and Applications (pp. 3-25), Malden, MA: Wiley-Blackwell. https://doi.org/10.1002/9781444303070.ch1

Yavuzer, H. (1996). Child and Crime. İstanbul: Remzi Bookstore.

Y1lmaz, M. T. (2009). Investigation of the relationship between self-compassion and parental attitudes of university students (Master's Thesis, University of Selçuk, Konya, Turkey). Retrieved from https://tez.yok.gov.tr

\section{Copyrights}

Copyright for this article is retained by the author(s), with first publication rights granted to the journal.

This is an open-access article distributed under the terms and conditions of the Creative Commons Attribution license which permits unrestricted use, distribution, and reproduction in any medium, provided the original work is properly cited. 